\title{
COLOUR THEREPY-BOON TO MANKIND
}

Dr.Sajan Kurien Mathew

HOD (Applied Arts)

Raja Man Singh Tomar Art and Music University, Gwalior

Colour Therapy is a complementary therapy for which there is evidence dating back thousands of years to the ancient cultures of Egypt, China and India. Colour is simply light of varying wavelengths, thus each colour has its own particular wavelength and energy. "Colour affects our life. Colour is physical..........we see it. Colour communicates............we recieve information from the language of colour. Colour is emotional..........it evokes our feeling."1

The energy relating to each of the seven spectrum colours of red, orange, yellow, green, blue, indigo and violet, resonates with the energy of each of the seven main chakras/energy centres of the body."The brightness of the colour of a substance depends very little on the preponderance of one colour vibration, of one spectrum line, in the light it reflects." 2 If you can imagine the chakras as a set of cogs/wheels, they are rather like the workings of a clock or an engine; each $\mathrm{cog} /$ wheel needs to move smoothly for the clock/engine to work properly. Thus good health and wellbeing is achieved by a balance of all these energies. Balance of the energy in each of the body's chakras is very important for health and wellbeing. Colour therapy can help to re-balance and/or stimulate these energies by applying the appropriate colour to the body and therefore re-balance our chakras.

Red relates to the base chakra, orange the sacral chakra, yellow the solar plexus chakra, green the heart chakra, blue the throat chakra, indigo the brow chakra (sometimes referred to as the third eye) and violet relates to the crown chakra.

Colour is absorbed by the eyes, skin, skull our 'magnetic energy field' or aura and the energy of colour affects us on all levels, that is to say, physical, spiritual and emotional. Every cell in the body needs light energy - thus colour energy has widespread effects on the whole body. There are many different ways of giving colour, including; Solarized Water, Light boxes/lamps with colour filters, colour silks and hands on healing using colour." The principles of the art are not hard and fast rules that a painter was bound to observe, but rather standards of perfection in performance towards which all painters could aspire." 3 By nature, human beings love to beautify themselves and their surroundings." This tendency shows itself in every place and age." 4

Colour therapy can be shown to help on a physical level, which is perhaps easier to quantify, however there are deeper issues around the colours on the psychological and spiritual levels. Our wellbeing is not, of course, purely a physical issue. Fortunately, many more practitioners, both orthodox and complementary are now treating patients in an holistic manner. That is to say, we are body, mind and spirit and none of these areas function entirely alone; each has an effect upon 


\section{INTERNATIONAL JOURNAL Of RESEARCH -GRANTHAALAYAH

the other. This is why Colour Therapy can be so helpful since colour addresses all levels of our being.

As babies we first experience colour in the womb where we are enveloped in a nurturing and comforting pink. Then as a child we associate with colour as part of our first learning processes. These first associations contribute to our consciousness. As we get older we attach many different feelings, memories and meanings to certain colours and this can then become a feature in our subconscious. We can build up prejudices to colours which have happy, sad, or frightening connotations for us.

All life experiences make an impression upon us. Some experiences will be positive and some negative. It is these negative experiences which can manifest themselves physically over time as dis-ease. As an example:- perhaps we have, over the years, been in a situation where we have felt unable, for one reason or another, to speak our mind, or to express our own truth. This can manifest as a problem in the throat chakra. The throat chakra relates in the spiritual aspect to self expression. Thus, if our self expression has been blocked, the energy in this area will not be free flowing and in turn this can lead to a physical manifestation of dis-ease.

Noting strong colour preferences can also be a helpful aid to finding possible problems and working with the appropriate colour/colours to help to dispel negative feelings, free blocks and re-balance the body emotionally, spiritually and, in turn, physically.

Colour Therapy is a totally holistic and non-invasive therapy and, really, colour should be a part of our everyday life, not just something we experience for an hour or two with a therapist. Colour is all around us everywhere. This wonderful planet does not contain all the beautiful colours of the rainbow for no reason. Nothing on this earth is here just by chance; everything in nature is here for a purpose. Colour is no exception. All we need to do is to heighten our awareness of the energy of colour and how it can transform our lives. A professional therapist will help you to do this. The capacity for health and wellbeing is within us all.

Colour therapy is safe to use alone or alongside any other therapy whether orthodox medicine or another complementary therapy and is safe and helpful for adults, children and animals too.

Please be aware that no complementary therapy should be considered as an alternative to professional medical advice where necessary and no properly qualified complementary therapist would suggest that, neither would they suggest that you stop taking your medication etc. If you are taking medication you should consult the prescribing professional before you stop taking it.

\section{USING COLOUR TO BALANCE THE CHAKRAS OF THE BODY}

Each of the spectrum colours is simply light of varying wavelengths, thus each colour has its own particular energy. 


\section{INTERNATIONAL JOURNAL Of RESEARCH -GRANTHAALAYAH \\ A knowledge Repository}

Art

The energy relating to each of these spectrum colours resonates with the energy of each of the seven main chakras of the body.

If you can imagine the chakras/energy centres as a set of cogs/wheels, they are rather like the workings of a clock or an engine; each cog /wheel needs to move smoothly and at a similar speed for the clock/engine to work properly. Thus good health and well being is achieved by a balance of all these energies (or the smooth running of the cogs/wheels).

Colour therapy can help to re-balance these 'wheels' by applying the appropriate colour to the body and therefore re-balance our chakras. Listed below is each of the spectrum colours and the chakra which it relates to. Violet has the shortest wavelength and red the longest wavelength." When we see the real colour in nature, we are apt to complain of their unreality."5

\section{Colours and related Chakras}

\begin{tabular}{|l||l|l|}
\hline Colour & Chakra \\
\hline \hline Violet & & Crown \\
\hline \hline Indigo & & Brow \\
\hline Blue & & Throat \\
\hline \hline Green & & Heart \\
\hline \hline Yellow & & Solar Plexus \\
\hline \hline Orange & & Sacral \\
\hline \hline Red & & Base \\
\hline
\end{tabular}

\section{REFERENCES:-}

1. Color Harmony2- Whelan, Bride M.; Rockport Publishers, Inc, Massachusetts, 1994,p.7

2. The Painter's Eye- Grosser Maurice; Rinehart \$ Company,Inc. New York Toronto, 1951,p.119

3. Art in East and West-Rowland, Benjamin JR; Beacon Press, Boston, 1966,p.20

4. A History of Fine Arts in India and the West- Tomory, Edith; Orient Longman, 1989, p.xix

5. The Meaning of Art-Read Herbert; Penguin Books Faber and Faber, London, 2003,p.58 